\title{
Optimization of osmotic dehydration conditions of peach slices in sucrose solution using response surface methodology
}

\author{
Baljeet Singh Yadav • Ritika B. Yadav • Monika Jatain
}

Revised: 6 September 2010 / Accepted: 7 September 2010 / Published online: 6 February 2011

(C) Association of Food Scientists \& Technologists (India) 2011

\begin{abstract}
Osmotic dehydration (OD) conditions of peach slices were optimized using response surface methodology (RSM) with respect to sucrose concentration $\left(50-70^{\circ} \mathrm{B}\right)$, immersion time $(2-4 \mathrm{~h})$ and process temperature $\left(35-55^{\circ} \mathrm{C}\right)$ for maximum water loss (WL), minimum solute gain (SG) and maximum rehydration ratio (RR) as response variables. A central composite rotatable design (CCRD) was used as experimental design. The models developed for all responses were significant. All model terms were significant in WL except the quadratic levels of sucrose concentration and temperature whereas in $\mathrm{SG}$, linear terms of time and linear and quadratic terms of temperature were significant. All the terms except linear term of time and interaction term of time and sucrose concentration, were significant in RR. The optimized conditions were sucrose concentration $=69.9^{\circ} \mathrm{B}$, time $=3.97 \mathrm{~h}$ and temperature $=37.63{ }^{\circ} \mathrm{C}$ in order to obtain WL of 28.42 (g/100 g of fresh weight), SG of 8.39 (g/100 g of fresh weight) and RR of 3.38 .
\end{abstract}

Keywords Osmotic dehydration · Peach - Optimization · Response surface methodology $\cdot$ Sucrose solution

Peach (Prunus persica) is believed to be the native of China. It is cultivated throughout warm temperate and subtropical regions of the world. The fruit has yellow and white flesh, a delicate aroma and velvety skin in some cultivars. Peach is

\section{Jatain}

Department of Food Science \& Technology,

Chaudhary Devi Lal University,

Sirsa, India 125055

Present Address:

B. S. Yadav $(\bowtie) \cdot$ R. B. Yadav

Department of Food Technology, Maharshi Dayanand University, Rohtak, India 124001

e-mail: baljeetsingh.y@gmail.com considered as sodium free, fat free, cholesterol free and rich source of vitamin A and C (Sharma 2010). The processing of peach can maintain its freshness and increase its shelf-life leading to increased commercialization of peach. Among the various methods of processing intended for extended shelf life and freshness, freeze- drying produces highest quality products, but it is expensive method of preservation. Therefore, to save the perishable products like peach and maintain their freshness, osmotic dehydration is considered as one of the new, simple and inexpensive pretreatment method with low capital investment. Osmotic dehydration, due to its energy and quality related advantages, is gaining popularity as a complimentary processing step in the chain of integrated food processing. However, since osmotic dehydration is a slow process, various methods to increase the rate of mass transfer, such as application of high hydrostatic pressure, high electrical field pulses, ultrasound, vacuum and centrifugal force can also be used in osmotic dehydration systems (Rastogi et al. 2002).

Osmotic dehydration (OD) is a method for the partial dehydration of water-rich foods, such as fruits and vegetables, by immersing them in concentrated solutions of sugar or salt (Raoult-wack 2002; Spiazzi and Mascheroni 1997). OD processes are normally designed with the aim of maximizing water removal meanwhile restraining solids uptake. The parameters which represent adequately the OD process are the water loss (WL) and solute gain (SG). The amount of water which diffuses from the fruit to the solution is the WL while the SG indicates the solids which diffuse from the solution to the fruit less the solids of the fruit which are migrated to the solution. The third stream is connected with the elution of low molecular weight substances like saccharides, organic acids, vitamins, minerals and salts. The quantity and rate of water removal depend on several variables and processing parameters like the weight loss, immersion time, agitation of solution, temperature, solution/ 
food ratio and specific surface area of the food (Singh et al. 2008; Ozdemir et al. 2008; EL-aouar et al. 2006; Lenart and Flink 1984). Osmotic agents that are used include sugar, glucose, corn syrup and sodium chloride.

Osmotic dehydration of fruits has recently received a lot of attention as a potential pre-treatment to conventional drying and freezing for improving the quality of fruit products and reducing energy consumption (Raoult-wack 2002; Nieto et al. 1998). This pre-treatment minimizes the thermal degradation of color and flavor, prevents enzymatic browning and thus limits the use of $\mathrm{SO}_{2}$ (Lenart and Grodeka 1989). Additionally, it has been found to improve nutrient retention during the subsequent convective drying process (Islam and Flink 1982).

Statistical designs are powerful tools used to study the main as well as the interactive effects of different process variables on a process. Among them, response surface methodology (RSM) is a collection of certain statistical techniques for designing experiments, building models, evaluating the effects of factors and searching for optimal conditions of desirable responses. RSM is an effective tool for optimization of a number of food processes including OD (Corzo and Gomez 2004). The main advantage of RSM is the reduced number of experimental runs that provide sufficient information for statistically valid results.

Osmotic dehydration process has been investigated for various fruits and vegetables like papaya (Kaleemullah et al. 2002), mushroom (Kar and Gupta 2003), beetroot (Manivannan and Rajasimman 2008), carrot (Sodhi et al. 2006) onion (Sutar and Gupta 2007) pineapple (Parjoko et al. 1996; Kumar and Devi 2010) apple (Conway et al. 1983; Janowicz and Lenart 2010), banana (Pokharkar and Prasad 1998). The process variables for the osmotic dehydration of pomegranate arils were successfully optimized using response surface methodology (central composite rotatable design) by Mundada et al. (2010). In the optimization of the osmotic dehydration process of the carrot cubes in mixtures of sucrose and sodium chloride by response surface methodology, using face-centered central composite design (CCF), the optimum osmotic dehydration process conditions for maximum water loss and minimum solute gain were: $50^{\circ} \mathrm{Brix}+15 \%$ w $/ \mathrm{v}$ sodium chloride solution, $54.8{ }^{\circ} \mathrm{C}$ solution temperature and 120 min process time (Singh et al. 2010). Shedame and Patil (2009) studied the effect of osmotic dehydration on the drying characteristics of grapes. Response surface methodology was also used to investigate the effect of sugar concentration (50$70^{\circ}$ Brix), solution temperature $\left(30-60{ }^{\circ} \mathrm{C}\right)$, solution to fruit ratio (4:1-8:1) and immersion time (60-180 $\mathrm{min})$ on the water loss, solute gain, rehydration ratio, vitamin-C loss, colour change and sensory overall acceptability of Indian gooseberry (aonla) slices (Alam et al. 2010). Rastogi and Raghavarao (2003) studied the osmotic dehydration kinetics of pineapple cubes over a range of concentration $\left(40-70^{\circ} \mathrm{B}\right)$ and temperature $\left(30-50{ }^{\circ} \mathrm{C}\right)$ of osmotic solution. Although there have been very few studies on the osmotic dehydration of peach also (Sahari et al. 2006; Giangiecome et al. 1987) but the studies on the optimization of process conditions for osmotic dehydration of peach are scanty. Therefore, the purpose of the present study was to investigate the effect of process variables of sucrose concentration, process duration and process temperature on WL, SG and RR during OD of peach slices and to establish optimum OD conditions.

\section{Materials and methods}

\section{Sample preparation}

Fresh, fully ripened peaches (Prunus perica) $(5 \mathrm{~kg})$ of Red heaven cultivar were purchased from a local market. The initial moisture content of the fresh peach was $88.5 \pm$ $0.90 .0 \%$. The fruits were washed, peeled, destoned and sliced into pieces of $20 \times 20 \times 5 \mathrm{~mm}$ before immersing them in different osmotic solutions.

\section{Osmotic solutions preparation}

Food grade sucrose was used as osmotic dehydrating agent and osmotic solutions of 50,60 and $70^{\circ} \mathrm{B}$ were prepared.

\section{Osmotic dehydration process}

The prepared fruit slices were immersed in desired osmotic solutions at 35,45 and $55{ }^{\circ} \mathrm{C}$ for 2,3 and $4 \mathrm{~h}$. For each experiment, $50 \mathrm{~g}$ of peach slices were put in to $500 \mathrm{ml}$ beakers containing $250 \mathrm{ml}$ of osmotic solutions of different concentrations preset at the desired temperature in a precision hot water bath $\left( \pm 1^{\circ} \mathrm{C}\right)$. The sample/solution ratio was kept as 1:5 (Kar and Gupta 2003). After the specified immersion time, the osmotically dehydrated samples were quickly rinsed, gently blotted dry with absorbing paper in order to remove adhering osmotic solution and later weighed and analyzed. Triplicate samples were used for each experiment. The water content was determined by drying the samples in a hot air oven at $65{ }^{\circ} \mathrm{C}$ and $1.6 \mathrm{~m} / \mathrm{sec}$ air velocity. The same hot air drying conditions were used for dehydrating the osmotically dehydrated samples used for rehydration studies.

Water loss, solute gain and rehydration ratio

The equations given by Ozen et al. (2002) were used to calculate the water loss and solid gain during the osmotic dehydration process.

\footnotetext{
$\%$ Water loss $(\mathrm{WL})($ fresh weight basis $)=\frac{\mathrm{W}_{\mathrm{o}}-\mathrm{W}_{\mathrm{t}}+\left(\mathrm{S}_{\mathrm{t}}-\mathrm{S}_{\mathrm{o}}\right)}{\mathrm{W}_{\mathrm{o}}} \times 100$

$\%$ Solute gain $(\mathrm{SG})($ fresh weight basis $)=\frac{\mathrm{S}_{\mathrm{t}}-\mathrm{S}_{\mathrm{o}}}{\mathrm{W}_{\mathrm{o}}} \times 100$
} 
Where, $\mathrm{W}_{\mathrm{o}}$ is the initial weight $(\mathrm{g})$ of the peach slices, $\mathrm{W}_{\mathrm{t}}$ is the weight $(\mathrm{g})$ of the peach slices after osmotic dehydration for time $t$ in hours, $S_{o}$ is the initial weight of solids (dry matter) in the peach slices $(\mathrm{g})$, and $\mathrm{S}_{\mathrm{t}}$ is the weight of solids (dry matter) of peach slices after osmotic dehydration for time $\mathrm{t}(\mathrm{h})$.

Rehydration ratio (RR), which is used to measure water absorption by osmotically dehydrated and dried product was determined by soaking $15 \mathrm{~g}$ of each sample in a sufficient volume of water (approximately 30 times of weight of dried peaches) at room temperature for $12 \mathrm{~h}$. The slices were weighed after removing excess water with the help of absorbent paper.

Rehydration ratio $=\frac{\text { Weight of rehydrated peach }(\mathrm{g})}{\text { Weight of dehydrated peach }}$

\section{Theoretical considerations}

Factors affecting the osmotic dehydration of peach slices were investigated with a face centered central composite design (FCC) as used by Singh et al. (2008), the only difference being the consideration of three variables with three levels in the present study. The information provided by the FCC was used in the experimental design chosen to optimize the osmotic dehydration of sliced peaches. Three independent variables used were sucrose concentration $\left({ }^{\circ} \mathrm{B}\right)$, process temperature $\left({ }^{\circ} \mathrm{C}\right)$ and time $(\mathrm{h})$. The responses measured were water loss, solid gain and rehydration ratio. The low and high levels of constraints in the actual (uncoded) form were taken as $50-70^{\circ} \mathrm{B}$ for sucrose concentration, 35 $55{ }^{\circ} \mathrm{C}$ for temperature and $2-4 \mathrm{~h}$ for immersion time. Three different levels for each experiment in coded form were $-1,0$ and +1 . The levels of input variables in coded and uncoded form are given in Table 1. Further, it was assumed that three functions exist between each response and the input factors. A second order polynomial equation was fitted to the experimental data of each independent variable as given below.

$Y_{k}=B_{k 0}+\sum_{i=1}^{3} B_{k i} x_{i}+\sum_{i=1}^{3} B_{k i i} x_{i}^{2}+\sum_{i=1}^{3} B_{k i j} x_{i} x_{j}+e_{k}$

where $\mathrm{Y}_{\mathrm{k}}=$ response variable $\left(\mathrm{Y}_{1}=\right.$ water loss; $\mathrm{Y}_{2}=$ solute gain; $Y_{3}=$ rehydration ratio) and $x_{i}$ represent the coded

Table 1 Coded and uncoded values of variables and their levels

\begin{tabular}{llrrr}
\hline Independent variables & Coded levels & -1 & 0 & +1 \\
\hline Sucrose concentration $\left({ }^{\circ} \mathrm{B}\right)$ & $\mathrm{A}$ & 50 & 60 & 70 \\
Time $(\mathrm{h})$ & $\mathrm{B}$ & 2 & 3 & 4 \\
Temperature $\left({ }^{\circ} \mathrm{C}\right)$ & $\mathrm{C}$ & 35 & 45 & 55 \\
\hline
\end{tabular}

independent variables $(i=1,2,3=A, B, C$ respectively, where, $\mathrm{A}=$ solute concentration; $\mathrm{B}=$ process duration; $\mathrm{C}=$ process temperature), $B_{k 0}$ is the value of the fitted response at the center point of the design, $\mathrm{B}_{\mathrm{ki}}$, $\mathrm{B}_{\mathrm{kii}}$ and $\mathrm{B}_{\mathrm{kij}}$ are the linear, quadratic and interaction regression coefficients, respectively.

Experimental design

The experimental design along with values of various responses is given in Table 2. A face centered central composite design (FCC) with three independent variables at three levels was used to study the response pattern and optimum combinations of variables. RSM was applied to the experimental data using commercial statistical package (Design expert. 7.1.6 version, Statease USA). Twenty runs were defined using the above software.

The statistical significance of the terms in the regression equation was examined by analysis of variance (ANOVA). Three dimensional response models were generated. The response surface plots were generated for different variables, while holding the values of third variable as constant (at the central value). Such response surface plots give accurate geometrical representation and provide useful information about the behavioral system with experimental design. The models obtained were used to interpret the effect of various variables on the responses i.e. WL, SG and RR. The optimization of the osmotic dehydration process was aimed at finding the levels of three independent factors (sucrose concentration, time and temperature) which would give maximum possible WL, minimum SG and maximum RR.

\section{Results and discussion}

ANOVA was used to assess the effect of variables on the responses. The results of the second-order response surface model in the form of ANOVA are given in Table 3. The second order polynomial equation was regressed for all the responses at different processing conditions.

The response surface plots were generated to visualize the combined effect of two variables on a particular response. The sign and magnitude of the coefficients as given in Table 4 indicated the effect of variables on the responses. Negative sign of a coefficient at linear level indicated decrease in response value with an increase in level of the variable, whereas, at interactive level, the level of one variable increased while that of other decreased to give similar response values.

Water loss (WL)

As shown in Table 2, the maximum WL in osmotically dehydrated fruit slices observed was $31.3 \%$, while the 
Table 2 Outline of the experimental design (FCC) matrix and observed values of response variables

${ }^{\mathrm{a}} \mathrm{g} / 100 \mathrm{~g}$ of fresh weight

Table 3 Analysis of variance for response variable

A: Sucrose concentration; B:

Process time; C: Process

temperature

${ }^{a}$ Significant

${ }^{\mathrm{b}}$ Non significant

\begin{tabular}{lrrrrrrr}
\hline Standards & Run & Sucrose Conc. $\left({ }^{\circ} \mathrm{B}\right)$ & Time $(\mathrm{h})$ & Temp. $\left({ }^{\circ} \mathrm{C}\right)$ & $\mathrm{WL}^{\mathrm{a}}$ & $\mathrm{SL}^{\mathrm{a}}$ & $\mathrm{RR}$ \\
\hline 7 & 1 & -1 & +1 & +1 & 24.78 & 9.33 & 3.34 \\
9 & 2 & -1 & 0 & 0 & 19.38 & 8.36 & 3.28 \\
16 & 3 & 0 & 0 & 0 & 23.83 & 9.73 & 3.52 \\
20 & 4 & 0 & 0 & 0 & 23.83 & 9.73 & 3.54 \\
14 & 5 & 0 & 0 & +1 & 28.75 & 8.49 & 3.33 \\
5 & 6 & -1 & -1 & +1 & 24.46 & 9.11 & 3.49 \\
12 & 7 & 0 & +1 & 0 & 28.94 & 9.26 & 3.41 \\
1 & 8 & -1 & -1 & -1 & 17.22 & 8.09 & 2.84 \\
13 & 9 & 0 & -1 & 0 & 20.19 & 8.16 & 3.47 \\
11 & 10 & 0 & 0 & 0 & 27.33 & 8.89 & 3.55 \\
10 & 11 & +1 & +1 & +1 & 31.34 & 10.65 & 3.54 \\
8 & 12 & +1 & +1 & -1 & 28.42 & 8.36 & 3.4 \\
4 & 13 & +1 & 0 & 0 & 23.83 & 9.97 & 3.58 \\
17 & 14 & 0 & 0 & 0 & 23.92 & 9.12 & 3.47 \\
15 & 15 & 0 & 0 & 0 & 23.22 & 9.84 & 3.53 \\
18 & 16 & 0 & 0 & 0 & 23.87 & 9.85 & 3.56 \\
19 & 17 & 0 & -1 & -1 & 20.21 & 8.66 & 2.92 \\
3 & 18 & -1 & -1 & 20.35 & 7.83 & 3.21 \\
2 & 19 & +1 & +1 & 25.13 & 9.73 & 3.54 \\
6 & 20 & +1 & & & & & \\
\hline
\end{tabular}

\begin{tabular}{|c|c|c|c|c|c|c|c|}
\hline \multirow[t]{2}{*}{ Source } & \multirow[t]{2}{*}{ df } & \multicolumn{2}{|c|}{ Water loss } & \multicolumn{2}{|c|}{ Solute gain } & \multicolumn{2}{|c|}{ Rehydration ratio } \\
\hline & & SS & $p$-value & SS & $p$-value & $\mathrm{SS}$ & $p$-value \\
\hline \multirow[t]{2}{*}{$\mathrm{Model}^{\mathrm{a}}$} & 9 & & $<0.0001$ & & 0.0043 & & $<0.0001$ \\
\hline & & 267.36 & & 13.29 & & 1.22 & \\
\hline \multirow[t]{2}{*}{ A } & 1 & & $<0.0001$ & & 0.2366 & & $<0.0001$ \\
\hline & & 74.7 & & 0.38 & & 0.18 & \\
\hline \multirow[t]{2}{*}{ B } & 1 & & $<0.0001$ & & 0.0468 & & 0.9148 \\
\hline & & 76.42 & & 1.22 & & 2.67 & \\
\hline \multirow[t]{2}{*}{$\mathrm{C}$} & 1 & & $<0.0001$ & & 0.0007 & & $<0.0001$ \\
\hline & & 94.85 & & 5.49 & & 0.49 & \\
\hline \multirow[t]{2}{*}{$\mathrm{AB}$} & 1 & & $<0.0001$ & & 0.6429 & & 0.0795 \\
\hline & & 15.04 & & 0.054 & & 8.45 & \\
\hline \multirow[t]{2}{*}{$\mathrm{AC}$} & 1 & & 0.0057 & & 0.1003 & & 0.0011 \\
\hline & & 2.11 & & 0.78 & & 0.045 & \\
\hline \multirow[t]{2}{*}{$\mathrm{BC}$} & 1 & & 0.0032 & & 0.9775 & & 0.0103 \\
\hline & & 2.57 & & 2.00 & & 0.022 & \\
\hline \multirow[t]{2}{*}{$A^{2}$} & 1 & & 0.2689 & & 0.1033 & & 0.0089 \\
\hline & & 0.24 & & 0.77 & & 0.023 & \\
\hline \multirow[t]{2}{*}{$\mathrm{B}^{2}$} & 1 & & 0.0209 & & 0.1501 & & 0.0302 \\
\hline & & 1.29 & & 0.58 & & 0.014 & \\
\hline \multirow[t]{2}{*}{$\mathrm{C}^{2}$} & 1 & & 0.677 & & 0.0013 & & $<0.0001$ \\
\hline & & 0.032 & & 4.68 & & 0.47 & \\
\hline \multirow[t]{2}{*}{ Residual } & 10 & & & & & & \\
\hline & & 1.73 & & 2.38 & & 0.022 & \\
\hline \multirow[t]{2}{*}{ Lack of fit ${ }^{b}$} & 5 & & 0.0764 & & 0.0688 & & 0.22 \\
\hline & & 1.38 & & 1.93 & & 0.015 & \\
\hline \multirow[t]{2}{*}{ Pure error } & 5 & & 5 & & 5 & & \\
\hline & & 0.34 & & 0.45 & & 7.03 & \\
\hline \multirow[t]{2}{*}{ Total } & 19 & & 19 & & 19 & & \\
\hline & & 269.09 & & 15.67 & & 1.24 & \\
\hline
\end{tabular}


Table 4 Regression coefficients of different responses

\begin{tabular}{lccc}
\hline \multirow{2}{*}{ Factor } & \multicolumn{2}{l}{ Coefficients } & \\
\cline { 2 - 4 } & $\mathrm{WL}$ & $\mathrm{SG}$ & $\mathrm{RR}$ \\
\hline Intercept & 23.75 & 9.68 & 3.53 \\
$\beta_{1}$ & $2.34 * * * *$ & 0.17 & $0.11^{* * * *}$ \\
$\beta_{2}$ & $2.37^{* * * *}$ & $0.30^{*}$ & $1.398 \mathrm{E}-003$ \\
$\beta_{3}$ & $2.64 * * * *$ & $0.63 * * *$ & $0.19^{* * * *}$ \\
$\beta_{12}$ & $1.37^{* * * *}$ & 0.08 & 0.03 \\
$\beta_{13}$ & $-0.51^{* * *}$ & 0.31 & $-0.08^{* *}$ \\
$\beta_{23}$ & $-0.57 * * *$ & $5.000 \mathrm{E}-003$ & $-0.05^{* *}$ \\
$\beta_{11}$ & -0.13 & -0.23 & $-0.04 * *$ \\
$\beta_{22}$ & $0.30^{*}$ & -0.20 & $-0.03^{*}$ \\
$\beta_{33}$ & 0.05 & $-0.57^{* *}$ & $-0.18^{* * * *}$ \\
Adeq Precision & 49.98 & 9.20 & 27.15 \\
$\mathrm{R}^{2}$ & 0.99 & 0.85 & 0.98 \\
Adjusted $\mathrm{R}^{2}$ & 0.98 & 0.71 & 0.96 \\
Predicted $\mathrm{R}^{2}$ & 0.96 & 0.61 & 0.89 \\
PRESS & 11.12 & 15.34 & 0.12 \\
\hline
\end{tabular}

A: Sucrose concentration; B: Process time; C: Process temperature $* * * * p<0.0001, * * * p<0.005, * * p<0.01, * p<0.05$

minimum was $17.2 \%$. Table 3 indicated that model was significant and the lack of fit was non-significant showing the significance of model at both 1 and $5 \%$ level of significance. The coefficient of determination $\left(\mathrm{R}^{2}\right)$ was 0.99 and the predicted $\mathrm{R}^{2}$ of 0.96 was in reasonable agreement with adjusted $\mathrm{R}^{2}$ of 0.98 in case of WL (Table 4). All the model terms were significant in WL except the quadratic levels of sugar concentration and temperature. As shown in Table 4, all the process variables at linear level and solute concentration and process time at interaction level had positive effect on WL $(p<0.0001)$. The sugar concentration-temperature and time-temperature at interaction level affected the WL negatively at $0.5 \%$ level of significance. At quadratic level, only process time affected the WL at 5\% level of significance.

The response surface plots for WL scores in relation to time-sucrose concentration; temperature-sucrose concentration and temperature-time have been shown in Fig. 1. As the immersion time increased, there was a continuous increase in the WL at a specific sucrose concentration and with increase in sucrose concentration from 50 to $70^{\circ} \mathrm{B}$ at constant time, the water loss again increased (Fig. 1a). These results are in agreement with Park et al. (2002) who also observed an increase in water loss with increase in concentration of the osmotic agent. As the sucrose concentration was increased, water loss was more pronounced with increase in time showing the positive interaction effect of process time and sucrose concentration on WL. Increased concentration showed it pronounced effect on WL taking more time as further increase of sugar
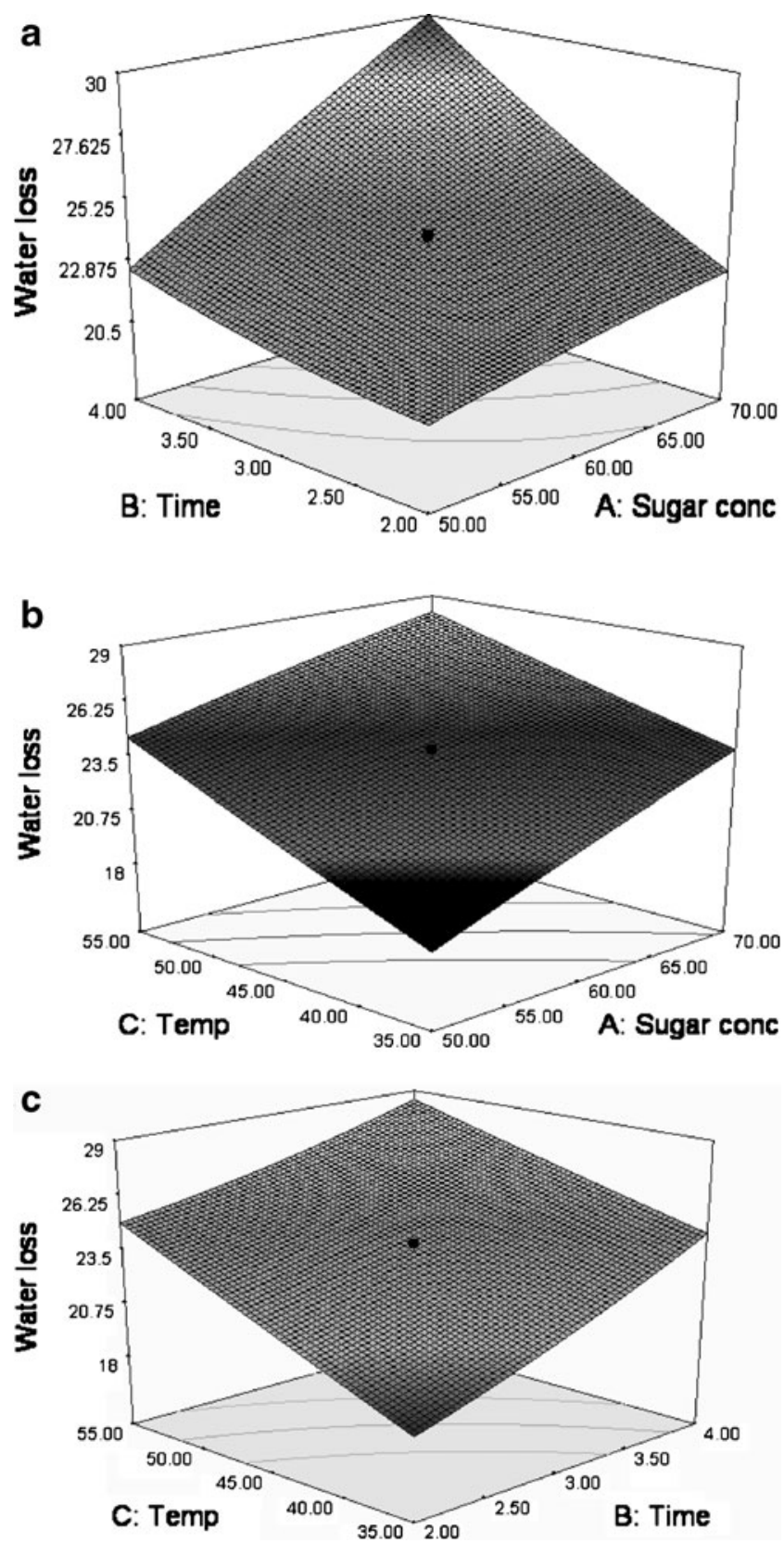

Fig. 1 Response surface and contour plots showing effect of processing variables on the $\mathrm{WL}$ a time v/s sucrose concentration (temperature $=45^{\circ} \mathrm{C}$ ); $\mathbf{b}$ temperature $\mathrm{v} / \mathrm{s}$ sucrose concentration (time $=$ $3 \mathrm{~h}$ ) and $\mathbf{c}$ temperature $\mathrm{v} / \mathrm{s}$ time (sucrose concentration $=60^{\circ} \mathrm{B}$ )

concentration reduces the water loss that might have lead to the sugar gain by the fruits which was not desirable (Rahman and Lamb 1990). This is attributed to the diffusion of water from dilute medium to the concentrated hypertonic solution developed in the fruit. As the temperature was increased at a specific sucrose concentration, there was a continuous increase in water loss. However, this increase was less pronounced at $70^{\circ} \mathrm{B}$ as compared to $50^{\circ} \mathrm{B}$ (Fig. 1b). The interactive effect of temperature and sucrose concentration showed a decreasing effect on WL after a certain level. 

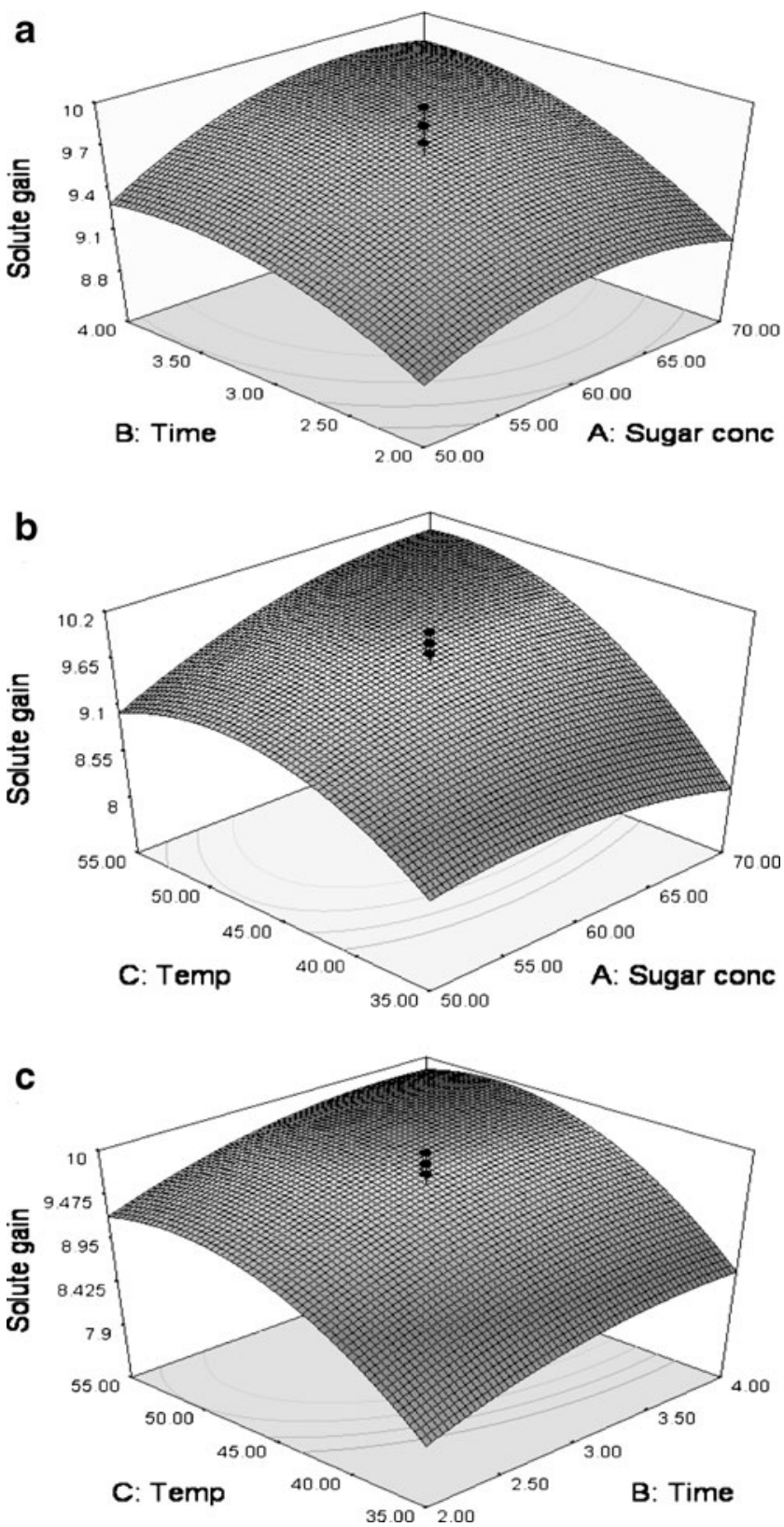

Fig. 2 Response surface and contour plots showing effect of processing variables on the SG a time v/s sucrose concentration (temperature $=45^{\circ} \mathrm{C}$ ); $\mathbf{b}$ temperature $\mathrm{v} / \mathrm{s}$ sucrose concentration (time $=$ $3 \mathrm{~h}$ ) and $\mathbf{c}$ temperature $\mathrm{v} / \mathrm{s}$ time (sucrose concentration $=60^{\circ} \mathrm{B}$ )

However, the interactive effect of time and temperature showed a decreasing effect on WL after a certain level (Fig. 1c). These results indicate an increase in WL with increase in osmotic solution temperature for specific immersion time. However, this increase was less pronounced when immersion time was increased to $4 \mathrm{~h}$ (Fig. 1c). The less pronounced increase in WL at high temperature maintained for higher time can be explained by the fact that further increase in temperature affects the semi-permeability of the cell walls and reduces the rate of osmosis. This may be due to reduction in viscosity of hypertonic solution and increase in diffusion coefficient of water increased at high temperature (Shahabuddin et al. 1990; Yao and Le Maguer 1996; Park et al. 2002). When immersion time was increased at a constant temperature, there was again an increase in water loss. Kim (1990) also reported an increase in the WL with increase in temperature during OD of apples as the rate of diffusion of water increased through semi permeable membrane with increase in temperature.
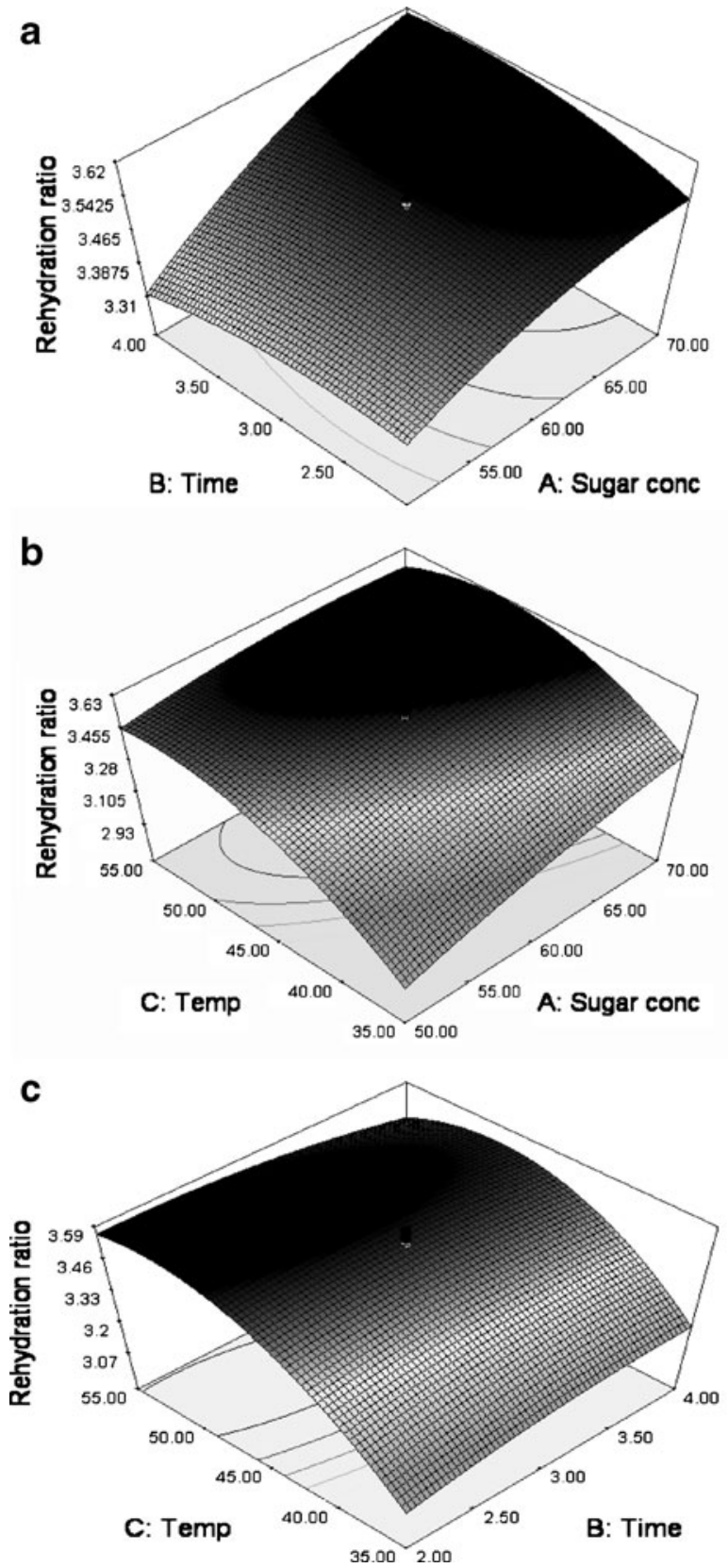

Fig. 3 Response surface and contour plots showing effect of processing variables on the RR a time $\mathrm{v} / \mathrm{s}$ sucrose concentration (temperature $=45^{\circ} \mathrm{C}$ ); $\mathbf{b}$ temperature $\mathrm{v} / \mathrm{s}$ sucrose concentration (time $=$ $3 \mathrm{~h}$ ) and $\mathbf{c}$ temperature $\mathrm{v} / \mathrm{s}$ time (sucrose concentration $=60^{\circ} \mathrm{B}$ ) 
The present results are also in agreement with those of Singh et al. (2007) who observed increase in WL with increase in osmotic solution temperature and process time but very slight increase with increase in osmotic solution concentration. Sahari et al. (2006) also observed higher water removal using more concentrated solution of sucrose (50 and 60\%) during osmotic dehydration of peach slices The concentration gradient between the intracellular fluid and solute solution caused the osmotic pressure, which lead to diffusion of water and solid molecules through semi-permeable membrane to achieve osmotic equilibrium. So the increase in solute concentration led to, increase in SG and WL.

\section{Solute gain $(\mathrm{SG})$}

It is evident from Table 3, the model was significant and lack of fit was non significant for SG, which again confirms that the model was significant at 1 and $5 \%$ levels of significance. The regression coefficients of $\mathrm{SG}$ with different terms of process variables are given in Table 4. In linear terms, time and temperature were found to be significant model terms with an increasing effect on SG ( $p<0.05$ and $<0.005$ respectively) whereas, sucrose concentration was non-significant model term.

However, effect of all the interactive terms on solute gain was non-significantly positive or negligible. These results are in agreement with findings of Singh et al. (2007) obtained during the optimization of the osmotic dehydration process for carrots. The quadratic effect of all the process variables was decreasing on SG with only temperature showing significant effect at $1 \%$ level of significance. The coefficient of determination $\left(\mathrm{R}^{2}\right)$ was 0.85 showing $85 \%$ variability in the data. The maximum SG attained during OD was 10.65 whereas the minimum was 6.84 (Table 2).

The SG increased with increase in immersion temperature and immersion time up to a level at a specific sucrose concentration and after it decreased. However, when the sucrose concentration increased from $50-70^{\circ} \mathrm{B}$, the increase in SG was more pronounced with increase in time as compared to increase in temperature (Fig. 2a and b). This positive interaction between process time and osmotic agent concentration was also reported by Manivannan and Rajasimman (2008) during the osmotic dehydration studies on beetroot in salt solution. When temperature was increased from 35$55^{\circ} \mathrm{C}$, the increase in $\mathrm{SG}$ was more pronounced after $4 \mathrm{~h}$ as compared to $2 \mathrm{~h}$ (Fig. 2c). The SG showed an initial increasing trend with increase in sucrose concentration and then declined when sucrose concentration reached to maximum level. The decrease in SG with increase osmotic solution concentration might be attributed to high viscosity of more concentrated osmotic solution imparting resistance to solute penetration at solution and peach slice interface. These results are in agreement with those of Singh et al. (2007), who also observed an increase in SG with increase in osmotic solution temperature and process time, and a decrease in SG with increase in osmotic solution concentration.

\section{Rehydration ratio (RR)}

RR is used to measure water absorption by dehydrated product. Table 3 shows that model was significant and lack of fit was non significant for RR. The regression coefficients of RR with different terms of process variables are given in Table 4. In the linear terms, sucrose concentration and temperature were found to be significant model terms $(p<0.0001)$ having increasing effect on RR of the osmotically dehydrated product where as time was non significant model term. However, in the interactive terms, all terms were found significant $(p<0.01)$ with decreasing effect on RR except sucrose concentration-time interaction term which had positive but non-significant effect. The quadratic level of all the three process variables had significant decreasing effect on RR at 1, 5 and $0.01 \%$ levels of significance for sucrose concentration, time and temperature respectively. Variability in the data was observed to be $98 \%\left(\mathrm{R}^{2}=0.98\right)$.

The maximum RR attained during OD was 3.58 whereas minimum was 2.71 (Table 2). RR increased with increase in

Table 5 Constraints, criteria for optimization, solution along with predicted and actual response values

\begin{tabular}{|c|c|c|c|c|c|c|c|}
\hline Constraints & Goal & Lower limit & Upper limit & Importance & Solution & ARV & $\mathrm{CV} \%$ \\
\hline Sucrose concentration $\left({ }^{\circ} \mathrm{B}\right)$ & In range & 50 & 70 & 3 & 69.9 & - & - \\
\hline Time (h) & In range & 2 & 4 & 3 & 3.97 & - & - \\
\hline Temperature $\left({ }^{\circ} \mathrm{C}\right)$ & In range & 35 & 55 & 3 & 37.63 & - & - \\
\hline WL & Maximize & 17.22 & 31.34 & 3 & 28.42 & 28.00 & 5.60 \\
\hline SG & Minimize & 6.84 & 10.65 & 3 & 8.39 & 8.10 & 2.68 \\
\hline RR & Maximize & 2.71 & 3.58 & 3 & 3.38 & 3.32 & 1.88 \\
\hline
\end{tabular}

$A R V$ Actual response values

The predicted values and actual reported values for any response differed non-significantly $(p<0.05)$ 
sucrose concentration at a constant time. However, the increase in RR with increase in sugar concentration was more pronounced with increase in time (Fig. 3a). The increase in temperature resulted in increase in $R R$ at a particular sucrose concentration up to $45{ }^{\circ} \mathrm{C}$, after which a decline in RR was observed (Fig. 3b). However, this increasing effect of temperature on RR was less pronounced with increase in sucrose concentration. Similarly, the increase in temperature had an increasing effect on RR at a constant time with maximum increase at about $45{ }^{\circ} \mathrm{C}$. However, when immersion time was increased from 2 to $4 \mathrm{~h}$, the RR was less pronounced with increase in temperature at $4 \mathrm{~h}$ (Fig. 3c).

\section{Optimization}

Responses were numerically optimized in combination with design expert software. In order to optimize the process of osmotic dehydration the maximization of $\mathrm{WL}, \mathrm{RR}$ and minimization of SG were the considerations. Two solutions were obtained by RSM and depending upon the desirability of the process variables with observed and predicted values, one of the two solutions was selected for optimization of the process variables. The constraint criteria for optimization, solution along with predicted and actual values are shown in Table 5. Using the given criteria, process conditions were optimized at sucrose concentration of $69.9^{\circ} \mathrm{B}$, time $3.97 \mathrm{~h}$ and temperature $37.63{ }^{\circ} \mathrm{C}$ in order to obtain WL of $28.42 \%$, SG of $8.39 \%$ and RR of 3.38 . Experiments were conducted based upon solution obtained. The predicted and actual values for all responses were not statistically different at $5 \%$ level of significance as verified from $t$-test. The results showed that coefficient of variance (CV) of the responses were less than 5.6\%, which confirmed that the predicted and actual values of all the responses were in close agreement with each other. Therefore, optimum conditions obtained in the model may be recommended for osmotic dehydration of peaches.

\section{Conclusion}

Response surface methodology was effective in identifying the optimum processing conditions for OD of peach slices in osmotic aqueous solutions of sucrose having concentration in range of $50-70^{\circ} \mathrm{B}$, temperature of $35-55^{\circ} \mathrm{C}$ and process duration of $2-4 \mathrm{~h}$. The results clearly showed that models developed were appropriate to be used for predicting WL, SG and RR of peach slices within the experimental study. The OD of peach slices at optimum conditions of $69.9^{\circ} \mathrm{B}$ sucrose concentration, $3.97 \mathrm{~h}$ process duration and $37.63{ }^{\circ} \mathrm{C}$ process temperature would reduce the original water content of the peach slices by about $28.42 \%$ with a rehydration ratio of 3.38 .
Therefore, OD of peach could effectively be used as a pretreatment prior to freezing or air drying to reduce energy costs and maintain the naturalness of the product.

\section{References}

Alam MS, Singh A, Sawhney BK (2010) Response surface optimization of osmotic dehydration process for aonla slices. J Food Sci Technol 47(1):47-54

Conway J, Castaigne F, Picard C, Vovan X (1983) Mass transfer considerations in the osmotic dehydration of apples. Can Inst Food Sci Technol J 16:25-29

Corzo O, Gomez ER (2004) Optimization of osmotic dehydration of cantaloupe using desired function methodology. J Food Eng 64:213-219

EL-aouar AA, Azoubel PM, Jr B, Murr FEX (2006) Influence of the osmotic agent on the osmotic dehydration of papaya (Carica papaya). J Food Eng 75:267-274

Giangiecome R, Torreggiani D, Abbe E (1987) Osmotic dehydration of fruit, part I. Sugar exchange between fruit and extraction syrups. J Food Process Preserv 11:83

Islam MN, Flink JM (1982) Dehydration of potato II. Osmotic concentration and its effect on air drying behavior. J Food Technol 17:387-403

Janowicz M, Lenart A (2010) Some physical properties of apples after low pressure osmotic dehydration and convective drying. Chem Process Eng 31:237-252

Kaleemullah S, Kailappan R, Varadharaju N, Devdas CT (2002) Mathematical modelling of osmotic dehydration kinetics of papaya. Agricultural mechanization in Asia, Africa, Latin America 33:30-34

Kar A, Gupta DK (2003) Air drying of osmosed button mushrooms. J Food Sci Technol 40:23-27

Kim MH (1990) Osmotic concentration of apples and its effects on browning reaction during air dehydration. J Korean Sci Nutri 9:121-125

Kumar PS, Devi P (2010) Optimization of some process variables in mass transfer kinetics of osmotic dehydration of pineapple slices. Int Food Res J (In press).

Lenart A, Flink JM (1984) Osmotic concentration of potato II. Spatial distribution of the osmotic effect. J Food Technol 19:65-89

Lenart A, Grodeka E (1989) Influence of the kind of osmotic substance on the kinetics of convection drying of apples and carrots. Food Tech Nutr 18:27-35

Manivannan P, Rajasimman M (2008) Osmotic dehydration of beetroot in salt solution: optimization of parameters through statistical experimental design. Int J Chem Biomol Eng 1(4):215222

Mundada M, Singh B, Maske S (2010) Optimization of processing variables affecting the osmotic dehydration of pomegranate arils. Int J Food Sci Technol 45:1732-1738

Nieto A, Salvatori D, Castro MA, Alzamora SM (1998) Air drying behavior of apples as affected by blanching and glucose impregnation. J Food Eng 36:63-79

Ozdemir M, Ozen BF, Dock LL, Floros LD (2008) Optimization of osmotic dehydration of diced green peppers by response surface methodology. LWT Food Sci Technol 41:2044-2050

Ozen BF, Dock LL, Ozdenir M, Floros JD (2002) Processing factors affecting the osmotic dehydration of diced green peppers. Inter $\mathrm{J}$ Food Sci Technol 37:497-502

Parjoko, Rahman MS, Buckle KA (1996) Osmotic dehydration kinetics of pineapple wedges using palm sugar. LWT - Food Sci Technol 29:452-459 
Park KJ, Bin A, Brod FPR, Park THKB (2002) Osmotic dehydration kinetics of pear d'Anjou (Pyrus communis). J Food Eng 52:293-298

Pokharkar SM, Prasad S (1998) Mass transfer during osmotic dehydration of banana slices. J Food Sci Technol 35:336-338

Rahman MS, Lamb J (1990) Osmotic dehydration of pineapple. J Food Sci Technol 27:150-152

Raoult-wack AL (2002) Recent advances in the osmotic dehydration of foods. Trends Food Sci Technol 5:46-51

Rastogi NK, Raghavarao KSMS (2003) Mass transfer during osmotic dehydration of pineapple: considering Fickian diffusion in cubical configuration. LWT Food Sc Technol 37(1):43-47

Rastogi NK, Raghavarao KSMS, Niranjan K, Knorr D (2002) Recent developments in osmotiv dehydration: methods to enhance mass transfer. Trends Food Sci Technol 13(2):48-59

Sahari MA, Souti M, Emam-jomeh Z (2006) Improving the dehydration of dried peach osmotic method. J Food Technol 4 (3): 189-193

Shahabuddin M, Hawader MNA, Rahman SMD (1990) Evaluation of characteristics of pineapple in the production of pineapple powder. J Food Process Preserv 14:375-391

Sharma R (2010) Nutrients and functional components in fruits and vegetables. Retrieved from http://www.ozscientific.com on May $12,2010$.
Shedame BM, Patil NB (2009) Effect of osmotic dehydration on drying characteristics. Int J Agric Eng 2(1):107-109

Singh B, Panesar PS, Gupta AK, Kennedy JF (2007) Optimization of osmotic dehydration of carrot cubes in sucrose-salt solutions using response surface methodology. Eur Food Res Technol 25:157-165

Singh B, Panesar PS, Nanda V (2008) Optimization of osmotic dehydration process of carrot cubes in sucrose solution. J Food Process Eng 31:1-20

Singh B, Panesar PS, Gupta AK, Kennedy JF (2010) Optimization of osmotic dehydration process of carrot cubes in mixtures of sucrose and sodium chloride solutions. Food Chem 123(3):590600

Sodhi NS, Singh N, Komal (2006) Osmotic dehydration kinetics of carrots. J Food Sci Technol 43(4):374-376

Spiazzi E, Mascheroni RH (1997) Mass transfer model for osmotic dehydration of fruits and vegetables I. Development of the simulation model. J Food Eng 34:387-410

Sutar PP, Gupta DK (2007) Mathematical modeling of mass transfer in osmotic dehydration of onion slices. J Food Eng 78:90-97

Yao Z, Le Maguer M (1996) Mathematical modeling and simulation of mass transfer in osmotic dehydration process. Part I: Conceptual and mathematical models. J Food Eng 29:349-360 